\title{
Improving Supervisor Evaluations Through the Use of Self-Determination Contracts
}

\author{
LEE L. WOODS \\ JAMES E. MARTIN
}

\begin{abstract}
Supervisor perceptions of employee competence in areas of work, social, and personal demands of the job often determine success or failure for the supported employee. This study involved three workers with disabilities who participated in a supported employment program. After being successfully hired in a job of their choosing, problems arose that jeopardized the successful completion of the placement phase. The workers used individualized self-determination contracts to improve supervisor evaluations. Specifically, they completed daily selfdetermination contracts to plan their work outcomes, manage their tasks, evaluate their performance, and make adjustments for their next opportunity to work. Results indicated that all three workers used selfdetermination strategies to improve their performance and meet the expectations of their respective employers.
\end{abstract}

Supported employment refers to paid work at or above minimum wage, in an integrated work setting, for individuals who need ongoing support to perform in a work setting. The Developmental Disabilities Act of 1984 (PL 98527) officially defined the term supported employment to ensure that persons with developmental disabilities achieve their maximum potential through increased independence, productivity, and integration into the community. Thus, employment in community jobs with support is a basic assumption underlying supported employment (Brooke, Wehman, Inge, \& Parent, 1995). Before the concept of supported employment emerged, vocational rehabilitation and educational programs trained people in sheltered workshops to "get ready" for community employment. Unfortunately, these programs transitioned very few people into community jobs. As a result, service providers, parents, and policymakers began to think that a different approach was needed to enable individuals to become gainfully employed (Bellamy, Rhodes, Mank, \& Albin, 1988; Whitehead, 1979).

Innovative research found that individuals with mental retardation could learn complex job skills (Bellamy, Horner, \& Inman, 1979; Gold, 1972; Mithaug, 1972). Demonstration projects followed showing that individuals with mental retardation could obtain and maintain community jobs (Rusch, Connis, 
\& Sowers, 1978; Rusch \& Mithaug, 1980; Wehman, 1981).

Supported employment evolved in three ideological phases. In the first phase, the employment specialist made all placement decisions regarding employment for clients. Rusch and Mithaug's (1980) train-and-place model exemplifies this phase. Martin, Mithaug, Oliphint, Husch, and Frazier (2002) describe this phase as "Get a Job-Any Job-and Keep the Individual at the Job." Employment specialists in this phase established relationships with area employers who had job openings in positions "within the capacity" of potential workers (Wehman \& Kregel, 1985). The employment specialist assessed the job requirements and the potential worker's skills in those areas, secured the job, and taught the worker any needed vocational or social skills. A potential worker then tried to meet the demands of the existing job. Once placed, the employment specialists addressed on-the-job work-related problems (e.g., productivity, accuracy, on-task), social problems (e.g., talk too much, too little), and personal problems (e.g., hygiene, appearance).

The second phase, "Get a Job That Is a Match for the Individual" (Martin et al., 2002), provided a structure whereby employment specialists consider what they think the potential worker might like to do, but excludes the individual from direct decision-making. Employment specialist perceptions of preferred job characteristics, skills, preferences, and needs determine a vocational profile, which is used to make employment decisions (Beyer \& Kilsby, 1997; McLoughlin, Garner, \& Callahan, 1987). The potential worker's work preferences contribute to making a job match, but in the end the employment specialist still makes the final decisions about the appropriateness of various jobs (Martin et al., 2002).

The third phase, or the self-directed employment phase, structured the employment process so that individuals with disabilities make job choice decisions. In this phase "the individual with a disability must be the one to select a career path after experiencing a variety of vocational experiences and supports" (Martin et al., 2002, p. 5).

Self-determination practices drive the third phase. Self-determination is a basic human right (Mithaug, 1993; Nirje, 1972). A self-determined person controls his own life and destiny (Wehmeyer, 1998). A self-determined person knows himself, values himself, has plans to achieve desired outcomes, acts on those plans, experiences outcomes (desired or otherwise) and learns from them, making adjustments for next time (Field \& Hoffman, 1994). Further, a self-determined person knows his personal needs, and makes choices based on those needs (Martin \& Mithaug, 1990). Martin and Marshall (1995) maintain that:

Self-determined people know how to choose-they know what they want and how to get it. From an awareness of personal needs, self-determined individuals choose goals, then doggedly pursue them. This involves asserting an individual's presence, making his or her needs known, evaluating 
progress toward meeting goals, adjusting performance, and creating unique approaches to solve problems. (p. 147)

Historically, people with disabilities often have had choices made for them and about them. Self-determination practices empower individuals to make their own choices.

Self-determination, as it pertains to supported emplovment, "encompasses a range of approaches with the broad aim of enabling people with disabilities to play an active role in developing their careers" (Kilsby \& Beyer, 2002, p. 125). For example, the Association of Persons in Supported Employment's (APSE) Ethical Guidelines for Professionals in Supported Employment (Di Leo, McDonald, \& Killam, 1996) mandate that opportunities be provided for individuals with disabilities to direct their own employment decisions and become involved in on-the-job problem solving.

Once on the job, workers may experience social, personal, or work problems that could interfere with job performance and continued employment. After workers learn what to do at a job site, the focus shifts to fluency, maintaining adequate productivity, and adjusting to changing job demands. Here honest and realistic supervisor feedback about workers' social, personal, and work performance initiates a process whereby workers compare their performance to supervisory standards. If performance falls short of expectations, workers develop a plan to improve performance. To do this, workers learn how to use self-determination contracts (Martin et al., 2002).

Self-determination contracts evolved from early work on self-management strategies. For example, the Adaptability Instructional Model (Mithaug, Martin, \& Agran, 1987) taught students with disabilities self-regulatory skills needed for school-to-work transitions including decision-making, independent performance, self-evaluation, and adjustment. The Adaptability Instruction Model evolved into the Self-Determined Learning Model of Instruction where success is determined not by simply adapting, but by actively changing existing circumstances to attain a more favorable outcome. This involves (a) setting a goal, (b) taking action, and (c) adjusting the goal or plan to attain the goal (Mithaug, Wehmeyer, Agran, Martin, \& Palmer, 1998; Wehmeyer, Palmer, Agran, Mithaug, \& Martin, 2000).

Self-determination contracts and goal-attainment strategies have been used successfully in schools. German, Martin, Huber Marshall, and Sale (2003) used self-determination contracts found in the Take Action: Making Goals Happen (Huber Marshall et al., 1999) lesson package to teach students to attain their IEP goals. Wehmeyer, Palmer, Agran, Mithaug, and Martin (2000) used the SelfDetermined Learning Model of Instruction to teach students to become causal agents in their own lives and increase their self-determination skills. Martin et al. (2003) used self-determination contracts to teach students self-regulation skills while completing academic tasks. 
Several types of self-determination contracts may be used to facilitate on-thejob problem solving, including work and social improvement contracts by allowing workers the opportunity to self-regulate their behavior (Martin, Mithaug, Agran, \& Husch, 1990). Specifically, self-determination contracts are designed to provoke engagement, engagement in turn impacts adjustments, and adjustments determine what changes individuals make (Martin et al., 2003). In this study, we examined the effects of self-determination contracts in a supported employment program to improve supervisor evaluations.

\section{METHOD}

\section{Participants}

Mitch, a 32-year-old man, had suffered a traumatic brain injury (TBI) as a result of a heart attack and subsequent lack of oxygen to the brain. A mechanical engineer prior to the incident, he had great difficulty adjusting to his newfound cognitive and motor challenges. He wanted to work and interacted well with most everyone, but often resisted help and was often unwilling to admit that there might be a concern regarding job performance.

Ty, a 25-year-old man, had a primary diagnosis of TBI and a secondary diagnosis of specific learning disability (LD). Prior to a motorcycle accident that caused his brain injury, he worked as a machinist while going to college. Ty also had difficulty adjusting to the various challenges introduced by his injury. Post injury, Ty had academic skills comparable to those of a typical student in the fourth grade, could tell time, and drive a car. Ty's interactions with supervisors and peers were considered to be generally appropriate, but attitude problems sometimes surfaced. Lack of motivation and a desire to socialize inhibited his productivity.

Eric, an 18-year-old man, had a diagnosis of autistic disorder/savant syndrome. School testing records indicated superior verbal-spatial and visualmotor functioning compared to his verbal functioning. Eric had just graduated from high school and wanted to work. He eagerly attempted most tasks presented to him. Unfortunately, he was of the opinion that his performance on the task attempted was perfect and, therefore, was not receptive to constructive criticism that presented him with ways to improve his on-the-job performance skills. Some tasks simply did not interest him. When asked to do a task that he was not interested in, his response was, "No, I can't do it."

\section{Settings}

Mitch chose a job at a factory through his association with a supported employment program. The factory supervisor at first requested minimal job coach support and wanted to do the initial training with natural supports. 
Mitch was initially assigned the task of "catching" products off of a press and stacking them on a rack as part of an assembly line. The task involved manipulating the pieces so they fit together properly before putting them on the rack. Fitting the pieces together required intense concentration from Mitch. This slowed him down, and put the entire line off schedule. Visualmotor difficulties combined with a stressful, noisy work environment made this task a poor match for Mitch.

Mitch subsequently tried a job in the bagging area, which was quiet and where he could work at his own pace. He filled $15 \mathrm{cu}$. ft. bags with packing material, marked an inventory sheet, and stacked the bags in the appropriate area. Mitch tallied each bag after completion in the correct (regular or antistatic) column and wrote the weight in the weight column. His tally marks tended to wander about the page, and he often forgot to write down the weight. Mitch had worked for about a month when his supervisor requested additional support. While the move to the bagging area was a positive step for both Mitch and his supervisor, the quality of his performance did not meet his supervisor's expectations. Mitch did not want a job coach working directly with him on site, but agreed to this arrangement when it was explained to him that his job was at stake.

Ty chose a job through his association with the supported employment program at a local machine shop working as a machinist's helper. Tasks included measuring and cutting stock, grinding, de-burring, counting and packaging finished products for shipment, daily cleanup duties, and other duties assigned by the supervisor. Ty had been working for about two weeks when the supervisor became concerned about his productivity.

Eric chose a job through his association with the supported employment program at a local fast-food restaurant where he maintained the salad bar. Eric was very distractible and struggled with several of the requirements of the task. Of particular concern was his apparent inattentiveness when given instructions and failure to follow the instructions.

\section{Design}

We used a replicated series of $\mathrm{AB}$ designs to demonstrate experimental control. This design is similar to the more traditional multiple-baseline design in that replication controls for threats to internal validity, but the subjects and settings had nothing in common, and the interventions took place at different points in time.

\section{Dependent Measure, Data Collection, and Agreement}

The supervisor's evaluation of "yes" or "no" on a daily evaluation card served as the dependent measure. Each worker's supervisor completed a daily evaluation card (see Figure 1). The card addressed worker performance of job 
Figure 1. Supervisor evaluation card.

\begin{tabular}{|l|l|l|}
\hline \multicolumn{3}{|c|}{ Supervisor's Evaluation } \\
\hline Name:_ategory & Met Requirements? & Comments \\
\hline Social & Yes No No & \\
\hline
\end{tabular}

requirements in the areas of work (actual tasks of the job), social (interactions with supervisors and peers), and personal (appearance, hygiene, etc.). To verify the accuracy of recording the yes or no responses from the cards to contracts to graphs, an independent observer determined that the researchers recorded $100 \%$ of Mitch's and Eric's data accurately. Because supervisor concerns primarily included job task performance and the workers consistently met the expectations for social and personal aspects of the job, Figure 5 shows only evaluations on the "work" portion of the supervisor evaluation card.

\section{Baseline}

During baseline, the three individuals performed their job tasks per normal working conditions. Baseline procedures included praise, error correction, and instruction. Each worker's supervisor taught the worker the basic job tasks with the help of the job coach. Supervisors and job coaches provided praise and error correction. Supervisors filled out evaluation cards at the end of each shift and indicated whether the worker met employer expectations. A stable baseline of at least three consecutive negative supervisor evaluations for the "work" portion of the evaluation card was established for each participant.

\section{Intervention}

Self-determination contracts addressed the individual needs of each worker and his supervisor's expectations. At the start of each workday, the worker filled out a contract by setting at least one goal to work on for the day. After setting the goal, the worker then devised a plan to achieve the goal, started his shift, and concentrated on achieving the stated goal. After his shift, the worker 
Figure 2. Mitch's inventory sheet.

DALLY INVENTORY UPDATE

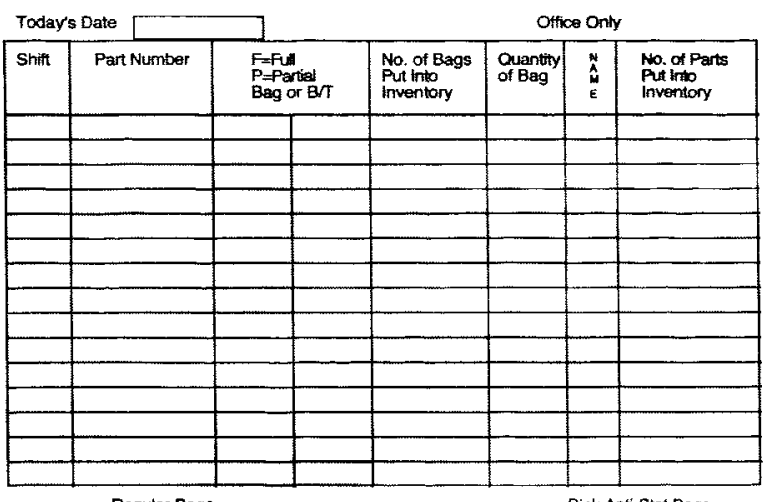

\begin{tabular}{|c|c|c|c|c|c|c|c|}
\hline 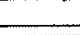 & Regular & & & & 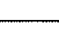 & nk Anti-S & \\
\hline Pelspan & Bagged & Date_ & & Pelspan - & Bagged & Date $_{\text {_ }}$ & \\
\hline Fogular & Weghts & Ano-stal & Wogrts & Peguturar & Weagns & And-stat & Weognts \\
\hline & & & & & 3 & & \\
\hline & & & 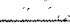 & &  & & \\
\hline & & & & & & & \\
\hline & & & & & & & \\
\hline & & & & & & & \\
\hline & & & & & $\ldots$ & & \\
\hline & 1 & & & & & & \\
\hline & os & & & & & & \\
\hline & 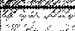 & & & & & & \\
\hline & & & & & & & \\
\hline rotal - Reg & ANg $W$ & $r_{\text {otal }-A S S}$ & Avg Wh & Trotal-Aeg & Avg.m & $r_{\text {orat }-A S}$ & Avg vit \\
\hline & & & & & & & \\
\hline
\end{tabular}

solicited feedback from his supervisor using the supervisor's daily evaluation card. Based on the feedback, the worker made adjustments to his self-determination contract. Any negative evaluation was addressed by a goal for improvement for next time. For example, if the worker received a "No" in the Work section of the evaluation for not working fast enough, he set a goal to work faster next time. When filling out his contract on the following workday, he checked his last contract to make sure that his goals addressed need areas.

As part of Mitch's selfdetermination contract, we modified his inventory sheet and introduced a selfinstruction component. We "cleaned up" the look of the inventory sheet and made the columns more distinct by color-coding them (see Figure 2). He now marked the regular packing material in the yellow column, the antistatic packing material in the pink column, and the weight in the blue column. His self-instruction phrase was "Mark in yellow (or pink), weigh in blue." As he said the phrase, he made the appropriate marks. Mitch received feedback from his supervisor via his supervisor evaluation card. He transferred that information to an improvement contract that he kept in a separate notebook.

Ty's self-determination contract consisted of a daily production sheet that allowed him to set goals for how many pieces he would produce each hour (see Figure 3). He self-evaluated his performance, compared the results to the shop standard, compared the results with his supervisor before setting goals for the next hour, and then asked himself if he made the company money that day. Finally, he set a goal for the next day's hourly goal completion.

Eric started the day by filling out an illustrated self-determination contract and marking a preset list of work, social, and personal goals and plans (see Figure 4). His supervisor evaluated Eric's performance and then Eric made adjustments for next time. 
CDEI, Fall 2004, 27:2

Figure 3. Ty's job production sheet.

Job Production Sheet

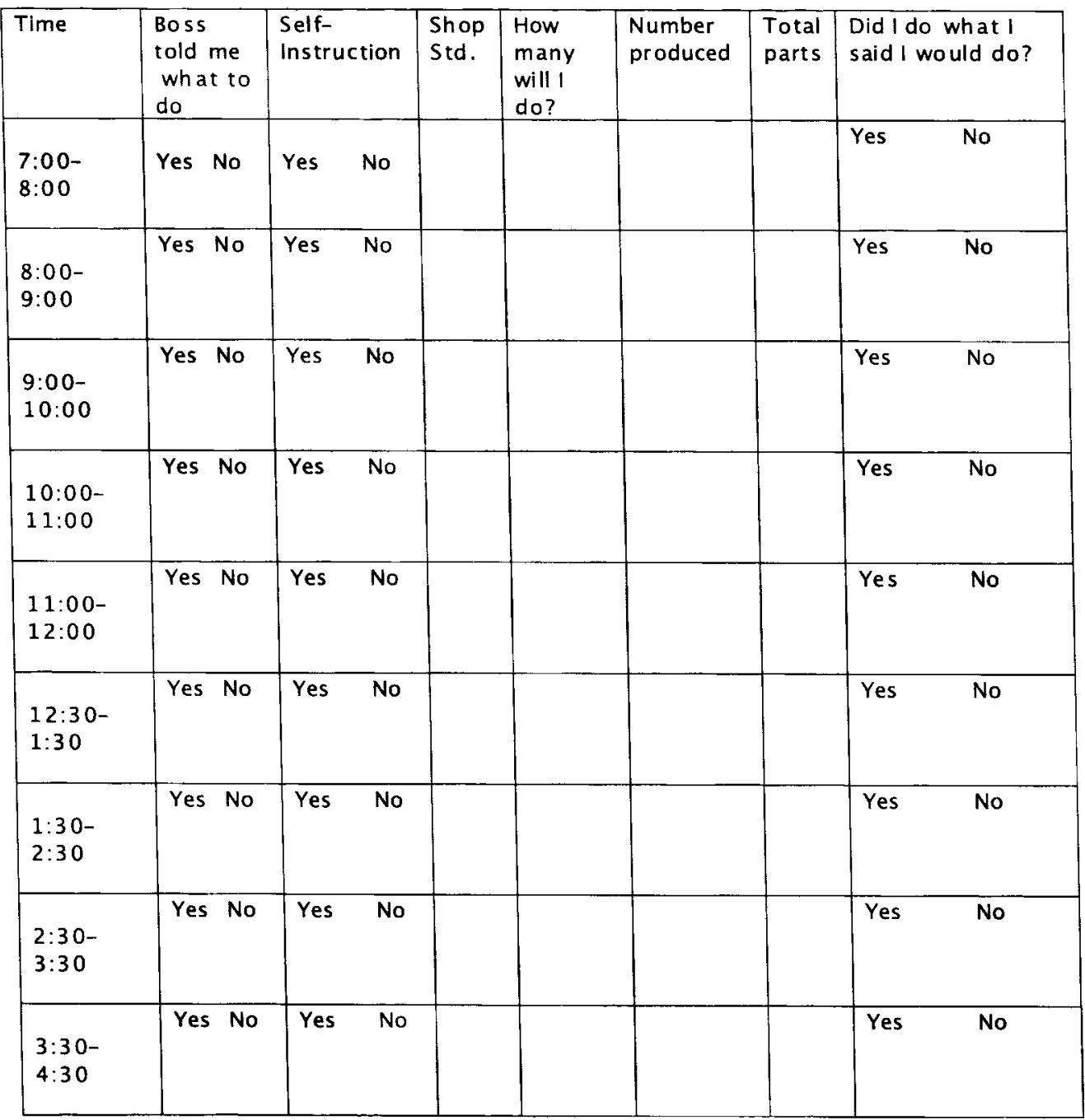

Did I meet my production goals for 6 out of 8 time blocks?

Yes No

Did I make my bos s money today?

Yes No

Tomorrow, in how many time blocks will I meet my hourly goal? 


\section{RESULTS}

After three days of "No" evaluations signifying that Mitch did not meet supervisor expectations for work, we introduced the self-determination contract package (see Figure 5). Mitch continued to receive "No" evaluations the first three days of intervention. On the fourth day of intervention, Mitch received a "Yes" evaluation from his supervisor. After eight consecutive days of positive evaluations, supervisor feedback cards were faded to once every three to five days. Maintenance probes were all positive. Mitch's percentage of workdays with "Yes" evaluations went from $0 \%$ at baseline to $82 \%$ by the end of the intervention phase.

Ty received his self-determination contract after 14 days of baseline. During this time Ty received six "Yes" evaluations and eight "No" evaluations. During the intervention phase, Ty received three straight "No" evaluations, followed by 23 consecutive "Yes" evaluations from his supervisor. Ty's percentage of workdays with "Yes" evaluations went from $43 \%$ at baseline to $88 \%$ by the end of the in tervention phase.

Eric received error feedback, praise, and instruction from his supervisor during baseline. In 20 days of baseline, Eric received 7 "Yes" evaluations and 13 "No" evaluations. After an initial "No" evaluation after

Figure 4. Eric's contract.

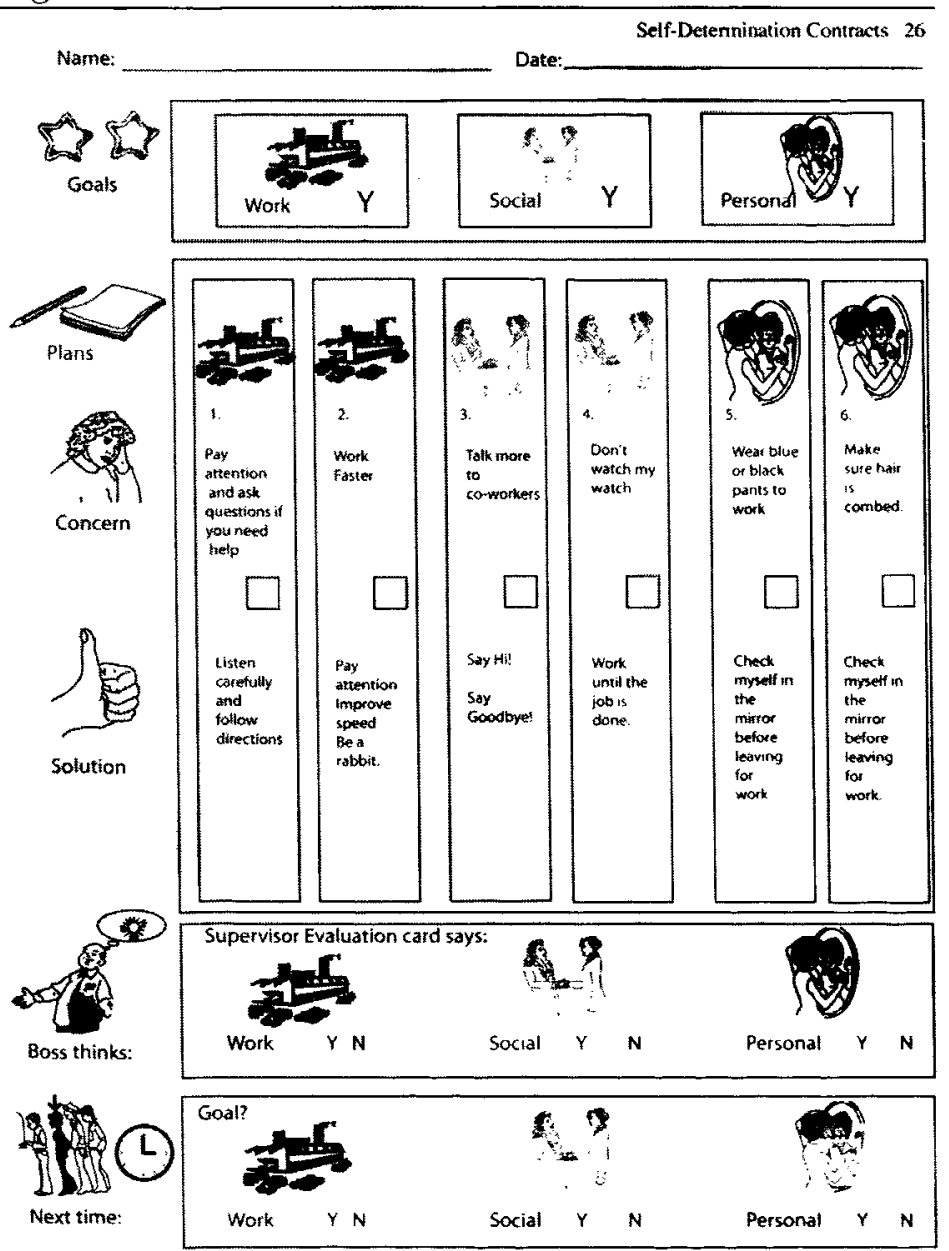


Figure 5. Changes in supervisor evaluations as a result of self-determination contracts.
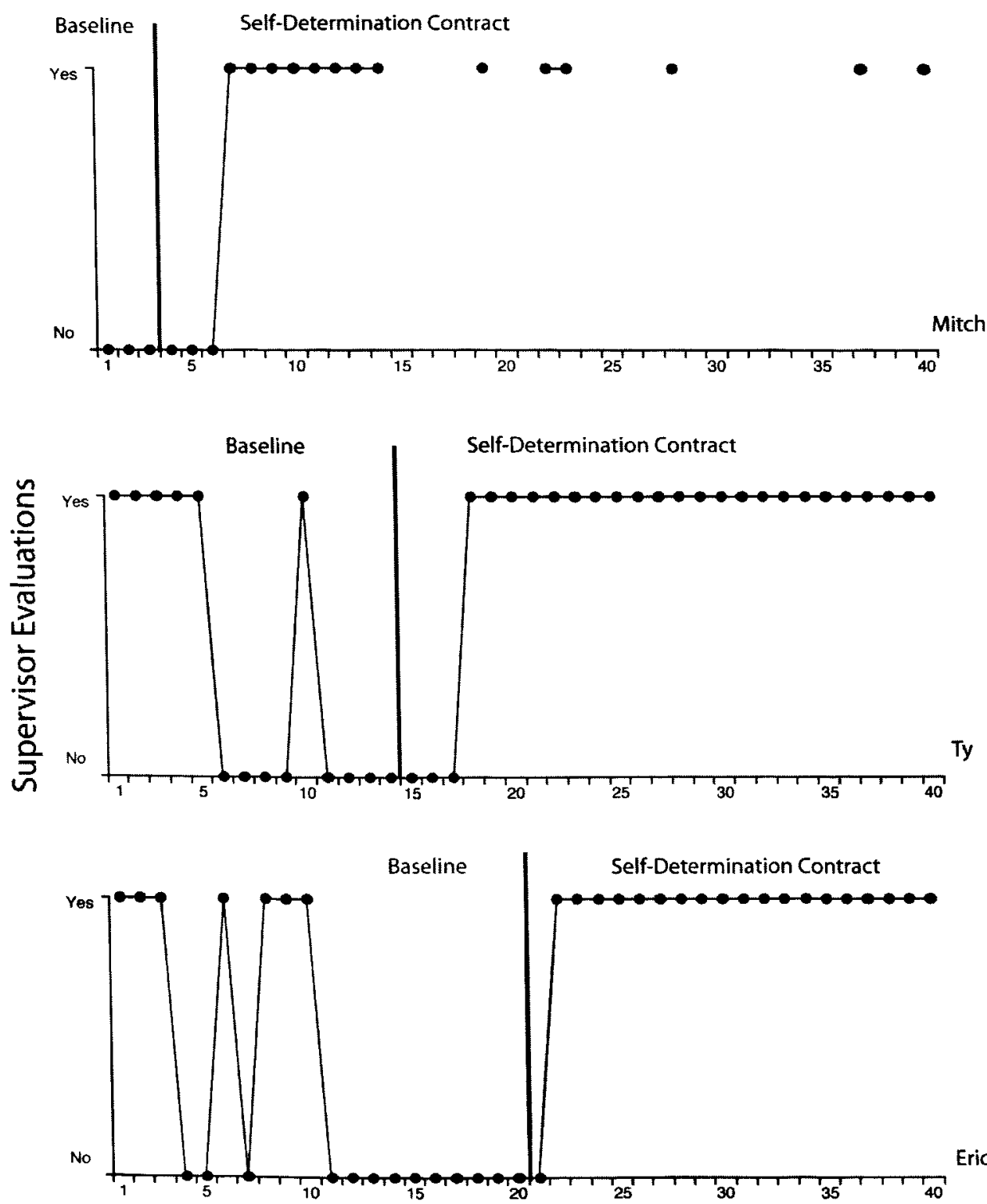
the introduction of the self-determination contract, Eric earned 19 consecutive "Yes" evaluations. Eric's percentage of workdays with "Yes" evaluations went from $35 \%$ at baseline to $95 \%$ by the end of the intervention phase.

\section{Discussion}

The three workers in this study participated in a supported employment program for adults with disabilities that embraced self-determination interventions. They had each successfully completed the community-based situational assessment phase of their supported employment program and had secured a desired placement in a community job, but each experienced on-the-job problems. In each case, employers requested additional support from the supported employment program's employment specialist, indicating that the individual's job might be at stake if performance did not improve. The three workers met employer expectations within four days of intervention. Their high rate of performance maintained for the remainder of the study. In each case, the worker saved his job due to a quick turn-around of behavior and consistent high performance.

This study demonstrated that self-determination contracts enabled participants to improve their on-the-job performance from job-threatening levels to levels that met their supervisor's expectations. Thus, the findings suggest that on-the-job fluency problems may be addressed by teaching the worker to use self-determination contracts.

The replicated $A B$ design used in this study suggests the effectiveness of the intervention through replication; however, the design may not have controlled for all possible internal validity threats. We used a multi-component intervention package to quickly improve supervisors' evaluations because the workers faced imminent termination. Unfortunately, we did not determine the effectiveness of the individual intervention components. It is conceivable that any one of the interventions alone might have resulted in observed improvements in the participants' job performance.

The $\mathrm{AB}$ data stream occurred at different points in time and independently of each other. Thus, we did not use a multiple-baseline design. According to Baer, Wolf, and Risley (1987), a good design does not need to be "imitated from a textbook," but needs to answer the research question convincingly (p. 319). In this study, this criterion was met by demonstrating that the use of selfdetermination contracts changed supervisor perceptions from negative to positive, removing the immediate threat of termination.

\section{Implications for Educators}

The Individuals with Disabilities Education Act (IDEA 1997) emphasizes that the purpose of special education is to prepare students for employment and 
independent living. To do this, the act mandates that a statement of needed transition services must be included in the IEP. Students whose desired course of study includes vocational training and community experience components may benefit from the use of self-determination contracts both in class and in their community experiences. Through these contracts, students learn to approach their supervisor for feedback on their performance, and that feedback in turn may be used to develop intervention programs.

Self-determination is "a combination of skills, knowledge, and beliefs that enable a person to engage in goal-directed, self-regulated, autonomous behavior" (Field, Martin, Miller, Ward, \& Wehmeyer, 1998, p. 2). By choosing work-related goals, making a plan to achieve those goals, managing behavior with those goals in mind, and making adjustments based on supervisor evaluations, workers and supervisors may address work-related problems and skill deficits in order to bring performance to levels that meet employer expectations.

The Adaptability Model considered adjustment a major component responsible for on-the-job success (Mithaug et al., 1987). Learning to adjust in the face of changing work demands, for instance, enables workers to achieve positive supervisor evaluations. The Self-Determined Learning Theory considers learning as adjustment. That is, individuals learn when impediments block goal achievement, and they make needed adjustments. In this study, the self-determination contracts brought together all of the information necessary to make the necessary adjustments.

Participants in supported employment and transition-age youth with disabilities should not be viewed as passive recipients of the actions of others. By using self-determination contracts, individuals with disabilities learn to set goals, evaluate their performance to a set standard, plan how to adapt on the job, and make the needed adjustments. While one does not become "self-determined" simply by using a self-determination contract, such contracts provide opportunities to learn and practice self-determined behavior. These critical skills empower workers to become successful and take control of their lives.

\section{REFERENCES}

Baer, D. M., Wolf, M. M., \& Risley, T. R. (1987). Some still-current dimensions of applied behavior analysis. Journal of Applied Behavior Analysis, 20, 313-327.

Bellamy, G. T., Horner, R. H., \& Inman, D. P. (1979). Vocational habilitation of severely retarded adults: A direct service technology. Baltimore: University Park Press.

Bellamy, G. R., Rhodes, L. E., Mank, D. M., \& Albin, J. M. (1988). Supported employment: A community implementation guide. Baltimore: Paul $\mathrm{H}$. Brookes.

Beyer, S., \& Kilsby, M. (1997). Supported employment in Britain. Tizard Learning Disabilities Review, 2, 6-14.

Brooke, V., Wehman, P., Inge, K, \& Parent, W. (1995). Toward a customer-driven approach of supported employment. Education and Training in Mental Retardation and Developmental Disabilities, 30, 308-320. 
Developmental Disabilities Act of 1984, PL 98-527, 42 U.S.C. $\iint 6000$ et seq.

Di Leo, D., McDonald, R., \& Killam, S. (1996). Ethical guidelines for professionals in supported employment. Richmond, VA: Association for Persons in Supported Employment (APSE). (Available at: http://www.apse.org/products.html)

Field, S., \& Hoffman, A. (1994). Development of a model for self-determination. Career Development for Exceptional Individuals, 17, 159-169.

Field, S. S., Martin, J. E., Miller, R. J., Ward, M., \& Wehmeyer, M. L. (1998). A practical guide for teaching self-determination. Reston, VA: Council for Exceptional Children.

German, S. L., Martin, J. E., Huber Marshall, L., \& Sale, R. P. (2000). Promoting selfdetermination: Using Take Action to teach goal attainment. Career Development for Exceptional Individuals, 23, 27-38.

Gold, M. (1972). Stimulus factors in skill training of the retarded on a complex assembly task: Acquisition, transfer, and retention. American Journal of Mental Deficiency, 76(5), $517-526$.

Huber Marshall, L., Martin, J. E., Maxson, L., Hughes, W., Miller, T., McGill, T., et al. (1999). Take action: Making goals happen. Longmont, CO: Sopris West.

Individuals with Disabilities Education Act (IDEA) Amendments of 1997, PL 105-17, 20 U.S.C. Jf 1400 et seq.

Kilsby, M. S., \& Beyer, S. (2002). Enhancing self-determination in job matching in supported employment for people with learning disabilities: An intervention study. Joumal of Vocational Rehabilitation, 17, 125-135.

Martin, J. E., \& Marshall, L. H. (1995). Choicemaker: A comprehensive self-determination transition program. Intervention in School and Clinic, 30, 147-156.

Martin, J. E., \& Mithaug, D. E. (1990). Consumer-directed placement. In F.R. Rusch (Ed.), Supported employment methods, models, and issues (pp. 87-110). Sycamore, IL: Sycamore.

Martin, J. E., Mithaug, D. E., Agran, M., \& Husch, J. V. (1990). Consumer centered transition and supported employment. In J. L. Matson (Ed.), Handbook of behavior modification with the mentally retarded (pp. 357-389). New York: Plenum Press.

Martin, J. E., Mithaug, D. E., Cox, P., Peterson, L. Y., Van Dycke, J. L., \& Cash, M. E. (2003). Increasing self-determination: teaching students to plan, work, evaluate, and adjust. Exceptional Children, 69, 431-447.

Martin, J. E., Mithaug, D. E., Oliphint, J. H., Husch, J. V., \& Frazier, E. S. (2002). Self-directed employment: A handbook for transition teachers and employment specialists. Baltimore: Paul Brookes.

McLoughlin, C. S., Garner, J. B., \& Callahan, M. J. (1987). Getting employed, staying employed: Job development and training for persons with severe handicaps. Baltimore: Paul H. Brookes.

Mithaug, D. E. (1972). The relation between programmed instruction and task analysis in the prevocational training of severely and profoundly handicapped persons. ASESPH Review, 4, 162-178.

Mithaug, D. E. (1993). Self-regulation theory: How optimal adjustment maximizes gain. Westport, CT: Praeger.

Mithaug, D. E., Martin, J.E., \& Agran, M. (1987). Adaptability instruction: The goal of transitional programming. Exceptional Children, 53, 500-505.

Mithaug, D. E., Wehmeyer, M. L., Agran, M., Martin, J. E., \& Palmer, S. (1998). The selfdetermined learning model of instruction: Engaging students to solve their learning problems. In M. L. Wehmeyer (Ed.), Making it happen: Student involvement in education planning, decision making, and instruction (pp. 299-328). Baltimore: Paul H. Brookes.

Nirje, B. (1972). The right to self-determination. In W. Wolfensburger (Ed.), The principle of normalization in human services (pp. 176-193). Toronto: National Institute on Mental Retardation.

Rusch, F. R., Connis, R. T., \& Sowers, J. (1978). The modification and maintenance of time spent attending to task using social reinforcement, token reinforcement, and response cost in an applied restaurant setting. Journal of Special Education Technology, 2, 18-26.

Rusch, F. R., \& Mithaug, D. E. (1980). Vocational training for mentally retarded adults. Champaign, IL: Research Press. 
Wehman, P. (1981). Competitive employment: New horizons for severely disabled individuals. Baltimore: Paul H. Brookes.

Wehman, P., \& Kregel, J. (1985). A supported work approach to competitive employment of individuals with moderate and severe handicaps. Joumal of the Association for Persons with Severe Handicaps, 10(1), 3-11.

Wehmeyer, M. L. (1998). Self-determination and individuals with significant disabilities: Examining meanings and misinterpretations. Journal of The Association for Persons with Severe Handicaps, 23(1), 5-16.

Wehmeyer, M. L., Palmer, S. B., Agran, M., Mithaug, D. E., \& Martin, J. E. (2000). Promoting causal agency: The self-determined learning model of instruction. Exceptional Children, $66,439-453$.

Whitehead, C. W. (1979). Sheltered workshops in the decade ahead: Work and wages, or welfare. In G. T. Ballamy, G. O'Connor, \& O. C. Karan (Eds.), Vocational rehabititation of severely handicapped persons (pp. 71-84). Baltimore: University Park Press.

\section{AUTHOR INFORMATION}

Lee Woods is a Doctoral Student in Special Education and Graduate Research Assistant, and James E. Martin, Ph.D., is the Zarrow Endowed Chair and Professor of Special Education at the University of Oklahoma.

\section{CONTACT INFORMATION}

Correspondence concerning this article should be addressed to Lee Woods, Zarrow Center for Learning Enrichment, 840 Asp Ave. room 111, Norman Oklahoma, 73019-4090. e-mail: lwoods@ou.edu. 